\title{
Recent advances in oxide film characterization
}

\author{
M. J. Graham \\ Institute for Microstructural Sciences, \\ National Research Council of Canada, Ottawa, Canada K1A OR6
}

\begin{abstract}
This paper considers the application of surface-analytical techniques to characterize both thin $(\sim 2 \mathrm{~nm})$ passive oxide films and thick (up to $1 \mu \mathrm{m}$ ) oxides formed on metals and alloys at high temperature. Auger electron spectroscopy (AES), X-ray photoelectron spectroscopy (XPS), Mössbauer spectroscopy, X-ray absorption near edge spectroscopy (XANES), secondary ion mass spectrometry (SIMS) and electron energy-loss (EEL) microscopy are considered. Emphasis is placed on the use of SIMS and EEL microscopy to provide chemical information at high spatial resolution. Characterization of oxide films on an atomic scale leads to a better understanding of the processes which take place during corrosion and oxidation.
\end{abstract}

\section{INTRODUCTION}

Modern surface-analytical techniques can provide useful information regarding the nature and chemical composition of electrochemically-formed passive oxide films on metals and alloys, and the transport processes which take place during oxide growth at both low and high temperatures. Surface techniques can be of two types: ex situ methods (where samples are removed from solution or a reaction vessel and placed in ultra-high vacuum systems), such as X-ray photoelectron spectroscopy (XPS), Auger electron spectroscopy (AES) and secondary ion mass spectrometry (SIMS), and in situ methods, such as infrared and Raman spectroscopy and X-ray absorption near edge spectroscopy (XANES). A summary of the ex situ techniques together with the information they provide is included in Table 1. This article concentrates on ex situ methods and will illustrate the application of various techniques to corrosion and oxidation research focused on the nature of passivity and the mechanism of growth and transport through oxide films.

\section{NATURE AND GROWTH OF ELECTROCHEMICALLY-FORMED OXIDE FILMS}

\section{Passive oxide film on iron}

The nature of the passive oxide film on iron has been the subject of investigation since the days of Michael Faraday. SIMS, Auger and XPS, etc., are ideally suited to examine this $1.6 \mathrm{~nm}$-thick film, whose precise nature and chemical composition are still a matter of some controversy. Our view is that the film is crystalline and consists of an inner magnetite $\left(\mathrm{Fe}_{3} \mathrm{O}_{4}\right)$ layer and an outer maghemite $\left(\gamma-\mathrm{Fe}_{2} \mathrm{O}_{3}\right)$ layer of which the outermost part is cation deficient. Others consider the film to be an amorphous gel with bridging di-oxy and di-hydroxy bonds. Surface-analytical data from our laboratory support the $\mathrm{Fe}_{3} \mathrm{O}_{4} / \gamma-\mathrm{Fe}_{2} \mathrm{O}_{3}$ duplex model (1). 
TABLE 1. Summary of surface-analytical techniques

\begin{tabular}{|c|c|c|c|c|c|}
\hline Technique & $\begin{array}{l}\text { Mersured } \\
\text { Particle }\end{array}$ & Process & Infornution & $\begin{array}{c}\text { P'robing } \\
\text { Dephe }\end{array}$ & $\begin{array}{c}\text { Spatiul } \\
\text { Resolution }\end{array}$ \\
\hline $\begin{array}{l}\text { X-ray Photoelectron } \\
\text { Spectroscopy (XPS or } \\
\text { ESCA) }\end{array}$ & $\begin{array}{l}\text { Photoelectrons } \\
\text { excited by soft } X \text {. } \\
\text { rays }\end{array}$ & X-ray & $\begin{array}{l}\text { - Elemental } \\
\text { analysis } \\
\text { - Chemical } \\
\text { bonding } \\
\text { - Depth profiles }\end{array}$ & $1.3 \mathrm{~nm}$ & $>50 \mu \mathrm{m}$ \\
\hline $\begin{array}{l}\text { Auger Electron } \\
\text { Spectroscopy (AES) }\end{array}$ & $\begin{array}{l}\text { Auger electrons } \\
\text { normally } \\
\text { excited by } \\
\text { incident electron } \\
\text { beam }\end{array}$ & $\bar{e}$ & $\begin{array}{l}\text { - Elemental } \\
\text { analysis } \\
\text { - Depth profiles }\end{array}$ & $1.3 \mathrm{~nm}$ & $>50 \mathrm{~nm}$ \\
\hline $\begin{array}{l}\text { Secondary Ion } \\
\text { Mass Spectrometry } \\
\text { (SIMS) }\end{array}$ & $\begin{array}{l}\text { Ions ejected from } \\
\text { surface by } \\
\text { primary ions }\end{array}$ & Ion & $\begin{array}{l}\text { - Elemental } \\
\text { trace analysis }\end{array}$ & $<1 n \mathrm{~m}$ & $>40 \mathrm{~nm}$ \\
\hline $\begin{array}{l}\mathrm{Fe}^{57} \text { Conversion } \\
\text { Electron Mössbauer } \\
\text { Spectroscopy (CEMS) }\end{array}$ & $\begin{array}{l}\text { Conversion and } \\
\text { Auger electrons } \\
\text { produced at } \\
\text { resonance by } \\
14.4 \mathrm{KeV} \gamma \text {-rays }\end{array}$ & $\begin{array}{c}\gamma-\text { ray } \\
2 \\
2\end{array}$ & $\begin{array}{l}\text { Fe-containing } \\
\text { phase } \\
\text { identification }\end{array}$ & $1 \mathrm{~nm}-0.5 \mu \mathrm{m}$ & $>1 \mathrm{~mm}$ \\
\hline
\end{tabular}

In particular, SIMS has been used to demonstrate the lack of hydroxyl ions within passive films (2); only a fraction of a monolayer of $\mathrm{OH}^{-}$is adsorbed on the outer oxide surface. Conversion electron (back-scattered) Mössbauer spectroscopy (CEMS) as seen in Table 1 is much more surface sensitive than the conventional transmission technique and has been used to examine passive oxide films on iron. The data can be interpreted in terms of the film being a small particle size crystalline oxide, and both CEMS and complementary XPS data support the model that the passive film resembles $\gamma-\mathrm{Fe}_{2} \mathrm{O}_{3}(3)$.

\section{Growth and breakdown of oxide films on iron and $\mathrm{Fe}-\mathrm{Cr}$ alloys}

With respect to the breakdown of passive oxide films and pitting corrosion, there has been considerable disagreement in the past regarding the role of chloride ion on the corrosion process. For example, it is questioned as to whether chloride ion is adsorbed on the oxide surface or is actually incorporated within the oxide film prior to pitting. We have shown using SIMS that anodic films formed on nickel contain up to $\sim 4 \% \mathrm{Cl}^{-}$from solution (4), whereas films on iron do not incorporate any $\mathrm{Cl}^{-}(5) . \mathrm{Cl}^{-}$is also incorporated into films on Fe-26Cr alloys after electropolishing in perchloric acetic acid (6). SIMS data shows that the inner part of the film is chromium-rich, the outer part iron-rich and that $\mathrm{Cl}^{-}$is incorporated into the oxide to a level approaching $~ 20 \%$ in the middle of the film. This $\mathrm{Cl}^{-}$ incorporation into the film influences the open-circuit breakdown behaviour, but, as in the case of nickel, was found to be not a precursor for pit initiation.

We have also used SIMS to study the air stability and growth mechanism of oxide films formed on iron and $\mathrm{Fe}-\mathrm{Cr}$ alloys in $\mathrm{H}_{2}{ }^{18} \mathrm{O}$-enriched solution (7-9). Films formed on iron at low potentials in the passive region were found to be unstable and thickened on exposure to the air. Films formed at higher potentials were air stable. 18O/SIMS data for additional oxide growth at higher potentials showed that the oxide grew by inward oxygen diffusion. Films formed on $\mathrm{Fe}$-Cr alloys were, rather surprisingly, less air stable than those formed on iron, and the extent of change increased with increasing chromium content of the alloy (9). Recently, the passive film on $\mathrm{Fe}-26 \mathrm{Cr}$ has been examined using the technique of in situ X-ray absorption near.edge spectroscopy (XANES) (10). During the X-ray spectroscopic 
measurements, the sample was maintained under electrochemical control in the $\mathrm{pH} 8.4$ borate buffer electrolyte. XANES established the presence of small amounts of $\mathrm{Cr}$ (VI) in the film, whose formation and reduction was reversible with potential. The $\mathrm{Cr}$ (VI) was not indefinitely stable in the atmosphere and was completely absent after many hours of air exposure.

\section{OXYGEN TRANSPORT IN CHROMIUM OXIDE, NICKEL OXIDE, AND ALUMINIUM OXIDE AT HIGH TEMPERATURE}

The performance of materials at high temperature is often controlled by the protective qualities of the surface oxide which forms. It is important, therefore, to understand the oxide growth processes in order to develop more corrosion-resistant coatings or alloys. SIMS analysis following sequential oxidation in $16 \mathrm{O}_{2}$ and $18 \mathrm{O}_{2}$ is an ideal way to study growth mechanisms, in particular the extent of inward oxygen transport compared with outward cation transport through the oxide scale. Often interpretation of the data is complicated by problems associated with interface broadening due to non-uniform sputtering and ion beam mixing. We have found that analyzing polyatomic species, e.g. of the type $\mathrm{M}^{16} \mathrm{O}_{2}^{-}, \mathrm{M}^{18} \mathrm{O}_{2}^{-}$and $\mathrm{M}^{16} \mathrm{O}^{18} \mathrm{O}^{-}$rather than the usual $16 \mathrm{O}^{-}$and $18 \mathrm{O}^{-}$ions largely overcomes these difficulties (11). It is possible using this polyatomic SIMS approach to distinguish grain boundary from lattice diffusion of oxygen, and to calculate diffusion coefficients.

\section{Chromium oxide}

Results for $\mathrm{Cr}_{2} \mathrm{O}_{3}$ formed on chromium at $900^{\circ} \mathrm{C}$ indicate that two independent oxygen diffusion processes occur during oxide growth (12). The first is isotropic oxygen selfdiffusion occurring at the interface between the $16 \mathrm{O}$ - and $18 \mathrm{O}$ - oxide layers. The second process is an anisotropic inward oxygen diffusion assumed to take place down oxide grain boundaries. The calculated diffusion coefficients for oxygen grain boundary diffusion are 2-3 orders of magnitude higher than those for isotropic diffusion, but are still orders of magnitude too low to account for the observed oxidation rates. The major growth transport is by outward chromium diffusion, but $\sim 1 \%$ of the oxide is created within the film as a result of inward oxygen diffusion.

The addition of small amounts of so-called 'reactive elements' such as cerium and yttrium increases the high temperature oxidation resistance of chromium and $\mathrm{Fe}-\mathrm{Cr}$ alloys. We have applied very thin $(4 \mathrm{~nm})$ reactive element coatings by sputtering ceria $\left(\mathrm{CeO}_{2}\right)$ or yttria $\left(\mathrm{Y}_{2} \mathrm{O}_{3}\right)$ directly onto chromium or $\mathrm{Fe}-\mathrm{Cr}$ substrates, and have used SIMS to determine the location of the reactive element within the oxide scale and to study its effect on transport processes (13). After oxidation at $900^{\circ} \mathrm{C}$ of ceria-coated $\mathrm{Fe}-26 \mathrm{Cr}$, cerium is detected within the oxide with its maximum signal observed to be away from the alloy/oxide interface. Long-term oxidations show that the location of the cerium maximum moves further towards the oxide/gas interface. If the $\mathrm{CeO}_{2}$ coating can be considered to be a stationary marker, its location towards the oxide/gas interface indicates that inward oxygen diffusion is becoming more predominant in governing oxide growth. $16 \mathrm{O}_{2} / 18 \mathrm{O}_{2}$ experiments confirm that oxygen transport is occurring. Examination of SIMS data in the form of the fraction of $18 \mathrm{O}$ associated with the cerium- and chromium- bearing species through the scale shows that a higher fraction is associated with the cerium- bearing species. If the cerium in the scale is located at oxide grain boundaries, the association of ${ }^{18} \mathrm{O}$ with cerium strongly suggests that transport of 180 through the scale occurs along grain boundaries. Therefore, coating $\mathrm{Fe}-\mathrm{Cr}$ alloys (or chromium metal) with a small amount of ceria (or yttria) causes a change in oxide growth mechanism from predominantly cation diffusion for uncoated material to predominantly anion diffusion via oxide grain boundaries. 
SIMS lacks the spatial resolution to determine the precise location of the cerium or its form and distribution within the chromium oxide layer. However, techniques such as transmission electron microscopy (TEM) with electron energy loss (EEL) analysis (14) can be used to identify cerium-chromium oxide phases formed at oxide grain boundary regions. EEL images illustrate the distribution of cerium-containing oxide and X-ray analysis in TEM shows these oxide particles to have a cerium to chromium ratio $\sim 1$ suggesting that the particles are the oxide $\mathrm{CeCrO}_{3}$, and this has been confirmed by electron diffraction measurements $(15,16)$. It is proposed that particles of $\mathrm{CeCrO}_{3}$, as well as cerium ions, retard the grain boundary diffusion of chromium cations to the extent that the mobility of oxygen anions along these grain boundaries exceeds that of the cations.

\section{Nickel oxide}

Our $160 / 18 \mathrm{O}$ SIMS results for nickel oxidation at $900^{\circ} \mathrm{C}(16,17)$ show that the major transport process during $\mathrm{NiO}$ growth is outward nickel diffusion. The data also show that the $\sim 1 \mathrm{~nm}$-thick air-formed film still exists at the metal/oxide interface after oxidation confirming growth by outward nickel diffusion. A similar result was obtained for chromium oxidation (12), demonstrating that the SIMS technique is sufficiently sensitive to allow a relatively thin layer of oxide to be detected underneath a very much thicker external scale. These prior oxide films, in fact, serve as very useful 'inert markers' for transport studies.

\section{Aluminum oxide}

Considering now the oxidation of aluminum-based alloys, transitional oxides such as $\gamma-\mathrm{Al}_{2} \mathrm{O}_{3}$ are usually formed at low temperatures and/or short oxidation times. Our SIMS data for $\gamma-\mathrm{Al}_{2} \mathrm{O}_{3}$ growth on $\mathrm{Fe}-8 \mathrm{Al}$ at $850^{\circ} \mathrm{C} \mathrm{(18)}$ and $\mathrm{Fe}-20 \mathrm{Al}$ at $800^{\circ} \mathrm{C} \mathrm{(17)} \mathrm{show} \mathrm{that} \gamma-\mathrm{Al}_{2} \mathrm{O}_{3}$ grows exclusively by outward aluminum diffusion. We have also used SIMS to study the growth of $\alpha-\mathrm{Al}_{2} \mathrm{O}_{3}$ scales on $\mathrm{Fe}-25 \mathrm{Al}(19,20)$ and $\beta-\mathrm{NiAl}(20)$ at $1100^{\circ} \mathrm{C}$. In this work, a liquid metal ion gun has been used to obtain SIMS profiles from areas as small as $3.5 \mu \mathrm{m} \mathrm{x}$ $3.5 \mu \mathrm{m}$ and images with $0.1 \mu \mathrm{m}$ lateral resolution. (Usually SIMS data, including the work described here for chromium and nickel, was obtained from areas $\sim 1 \mathrm{~mm}^{2}$ ). This high resolution data shows that the growth of $\alpha-\mathrm{Al}_{2} \mathrm{O}_{3}$ is complex. At $1100^{\circ} \mathrm{C}, \beta-\mathrm{NiAl}$ develops a ridged structure which grows by the outward diffusion of aluminum, whereas Fe-25Al grows by a mechanism involving outward aluminum diffusion and some inward oxygen diffusion along oxide grain boundaries. Oxygen diffusion is observed to play an increasing role in the oxidation of both $\mathrm{Fe}-25 \mathrm{Al}$ and $\beta-\mathrm{NiAl}$ as the temperature is raised to $1200^{\circ} \mathrm{C}(21)$.

\section{CONCLUDING REMARKS}

This article has given a brief overview of the application of surface-analytical techniques, in particular SIMS, Auger, XPS, Mössbauer and EEL microscopy, to study the structure and composition of surface oxide films. Advances in oxide film characterization are often achieved by the use of these complementary techniques. As the spatial resolution of SIMS improves, we will gain even more detailed insights into the processes involved in the corrosion and oxidation of metals and alloys.

\section{Acknowledgement}

The author thanks D.F. Mitchell, R.J. Hussey, B. MacDougall, R. Prescott, P. Papaiacovou, R. Goetz, D.A. Downham, J.A. Bardwell, V. Mitrovic-Scepanovic, M.E. Brett, K.M. Parkin, J. Shen, G.I. Sproule and J.W. Fraser for their contributions to this work. 
REFERENCES

1. M.J. Graham, J.A. Bardwell, R. Goetz, D.F. Mitchell and B. MacDougall, Corros. Sci., 31, 139 (1990).

2. D.F. Mitchell and M.J. Graham, J. Electrochem. Soc., 133, 936 (1986).

3. M.E. Brett, K.M. Parkin and M.J. Graham, J.Electrochem. Soc., 133, 2032 (1986).

4. B. MacDougall, D.F. Mitchell, G.I. Sproule and M.J. Graham, J.Electrochem. Soc., 130, 543 (1983).

5. R. Goetz, B. MacDougall and M.J. Graham, Electrochimica Acta, 31, 1299 (1986).

6. V. Mitrovic-Scepanovic, B. MacDougall and M.J. Graham, Corros.Sci., 24, 479 (1984).

7. R. Goetz, D.F. Mitchell, B. MacDougall and M.J. Graham, J. Electrochem. Sec, 133, 535 (1987).

8. J.A. Bardwell, Corres. Sci., 30, 1009 (1990).

9. J.A. Bardwell, G.I. Sproule, D.F. Mitchell, B. MacDougall and M.J. Graham, J.Chem. Soc. Faraday Trans, 87, 1011 (1991).

10 J.A. Bardwell, A.J. Davenport, H.S. Isaacs, G.I. Sproule, B. MacDougall and M.J. Graham, J. Electrochem. Soc, in press.

11. D.F. Mitchell, R.J. Hussey and M.J. Graham, J. Vac. Sci. Technol, A2, 789 (1984).

12. R.J. Hussey, D.F. Mitchell and M.J. Graham, Werkstoffe und Korrosion, 38, 575 (1987).

13. R.J. Hussey, P. Papaicovou, J. Shen, D.F. Mitchell and M.J. Graham, Proc. Symp. on Corrosion and Particle Erosion at High Temp., Ed. V. Srinivasan and K. Vedula, The Minerals, Metals and Materials Soc., p. 567 (1989).

14. D.F. Mitchell and M.J. Graham, J. Electrochem. Soc, 133, 2433 (1986).

15. D.A. Downham, R.J. Hussey, D.F. Mitchell and M.J. Graham, Proc. Symp. on High Temp. Oxidation and Sulphidation Processes, 29th Annual Conf. of Metallurgists, Pergamon Press Proc. Vol. 22, p. 101 (1990).

16. M.J. Graham, D.A. Downham, R.J. Hussey, D.F. Mitchell and G.I. Sproule, Proc. 4th Berkeley Conf on Corrosion-Erosion-Wear of Materials at Elevated Temp, Ed.

A.V. Levy, National Assoc. of Corr. Engineers, p. 4-1 (1991).

17. M.J. Graham, Proc. 1st Int Conf. on Microscopy of Oxidation, Ed. M.J. Bennett and G.W. Lorimer, The Inst. of Metals, p. 10 (1991).

18. M.J. Graham, J.I. Eldridge, D.F. Mitchell and R.J. Hussey, Mat. Sci. Forum, 43, 207 (1989).

19. R. Prescott, D.F. Mitchell, G.I. Sproule, R.J. Hussey and M.J. Graham, Proc. Int. Symp. on Solid State Chem, of Adv. Mat. Part B. High Temp. Corros of Adv, Mat, Japan, Dec. 1990, in press.

20. R. Prescott, D.F. Mitchell, G.I. Sproule and M.J. Graham, Solid State Ionics, in press.

21. M.J. Graham, R. Prescott and D.F. Mitchell, NACE 91, National Assoc. of Corr. Engineers, in press. 